\title{
CHAPTER
}

\section{The Touched Self}

\section{Affective Touch and Body Awareness in Health and Disease}

\author{
Antje Gentsch, Laura Crucianelli, Paul Jenkinson, \& Aikaterini Fotopoulou
}

\begin{abstract}
This chapter focuses on how interpersonal, affective touch shapes our sense of self as embodied beings. In the first section, we highlight the centrality of bodily representations for our psychological sense of self, with special emphasis on the role of internal bodily signals in forming the emotional, core of selfhood. The second section focuses on affective touch as a domain of interoception and addresses its important contribution to healthy body representation and bodily awareness. Specifically, we present recent, accumulating evidence in healthy volunteers pointing to the crucial role of affective touch in the construction and maintenance of fundamental facets of bodily awareness, such as the sense of body ownership. Finally, in a third section, we discuss findings in neurological and psychiatric disorders of body representation and awareness, indicating the importance of affective touch and other affiliative, interpersonal signals for the construction of a coherent, efficient and resilient sense of embodied selfhood. Overall, our chapter draws on perspectives from multiple mind and brain fields in order to highlight how affective touch, a bodily modality by which we can communicate social affiliation and care, has a fundamental role in the constitution of selfhood.
\end{abstract}

Keywords: body ownership, interoception, bodily self, affective touch, self-awareness, body representation, selfhood, insula, rubber hand illusion 


\section{Introduction}

The ability to perceive our body as distinct from other entities in the world and our ability to move it intentionally relies on the capacity to form mental representations of its structure, states and possibilities in space and time. These representations are also linked with fundamental facets of our psychological self, in the sense that we locate our self within the boundaries of our physical body and we perceive this particular body as belonging to the self and as being under its volitional control. Most of the time in our everyday life, however, we are not aware of these mental representations. Instead, we seem to become aware only of a small proportion of them and under specific circumstances. For example, we do not routinely think about the position of our arms or legs in space but we may do so if we are asked to perform a complex task for the first time. Similarly, we do not usually think of the shape of our body as it appears from the outside, but we may suddenly become 'self-conscious' of our appearance if a particularly attractive individual enters the room. Given the preconscious and elusive character of these representations, their particular content and subdivisions, as well as their reflective or pre-reflective nature remain controversial (Gallagher, 2000; see also below). Importantly, despite the centrality of these bodily representations for our sense of self, neuropsychology and experimental psychology have long demonstrated that our conscious awareness of the body is not infallible nor cognitively impenetrable. Indeed, psychologists have used several experimental 'tricks' to systematically manipulate sensorimotor signals, promote their integration, or generate conflicts and illusions, and hence study how the bodily self is constructed and maintained in the mind. In addition, while in such studies with healthy volunteers the particular manipulations of the bodily self are by necessity fully dependent on the duration and set-up of the experiment, neuropsychological and psychiatric disorders have revealed rich and long-lasting aberrations of body awareness. For example, brain damage to the perisylvian regions of the right-hemisphere may deprive 
patients of their normal sense of body ownership for the affected, left body parts, so that they may feel that their left arm is no longer theirs and instead belongs to a different person. In this sense, such disorders represent an indispensable window of insight into the psychological and neural processes of body representation and awareness.

Several scholars further argue that the bodily self is not something that depends solely on mental and brain processes that belong to the singular individual and its body. Instead the self is socially or intersubjectively constituted. The notion of a socially constituted self has had many different voices in science and the humanities. A common denominator in these perspectives is the incompleteness of the view of an individual responding to a world populated only by inanimate things. The self, and particularly the bodily self, is according to some scholars shaped from the very beginning by the encounter with other living beings and hence our self is seen as intrinsically intersubjective. Indeed, even in cognitive neuroscience, the once prevailing assumption that the human mind can be understood by examining exclusively cognitive functions and their neural correlates has undergone considerable criticism. A diverse and growing community of researchers claim that mental abilities are embedded in the acting, sensing and feeling body, and are subject to intricate couplings between organisms and their social environments (e.g., Damasio, 1994; Decety, 2009; Frith \& Frith, 2010; Panksepp, 1998; Rizzolatti \& Craighero, 2004; Sebanz, Bekkering, \& Knoblich, 2006). In this chapter, we will focus on affective touch, as a specific modality of interoception (see below) that in juxtaposition to cutaneous pain has clear affective quality (pleasure vs. unpleasure) and natural social meaning (care vs. harm).

\section{The Interoceptive and Emotional Core of the Bodily Self}




\subsection{What Constitutes the Bodily Self?}

What is the bodily self and how does it emerge? Questions about the mental representation of the body in relation to the self, have been of recurring interest throughout the history of sciences and the humanities, and have recently regained attention in brain sciences. Although debates regarding the precise nature of self-representation are ongoing, growing evidence suggests that abstract, metacognitive notions of selfhood may depend on more fundamental, somatic sources. The mechanism of integration of somatic experiences with other signals from the environment is thought to contribute in the first place to a nonconceptual basic form of self-awareness, which is also commonly referred to as the 'minimal self' (Damasio, 1999; Gallagher, 2000). A multitude of experimental paradigms have documented the mechanisms of integrating visual, vestibular, proprioceptive and tactile input that give rise to higher-level representations of our body (Blanke, 2012). This multisensory integration is considered to be at the core of our most basic sense of selfhood. Accordingly, at least two levels of self-awareness have been proposed: (i) a pre-reflective, non-conceptual form of bodily self-awareness ('minimal self'), which can distinguished from (ii) a conceptual self-knowledge that is based on beliefs, intentions and social-contextual cues ('narrative self', Gallagher, 2000). The 'narrative self' (or 'extended self'; Neisser, 1988) can be conceived of as a continuous, coherent self that is derived and reconstructed from autobiographical knowledge (Conway, 2001). In contrast, bodily self-awareness is regarded as an implicit internal, procedural model of the bodily self that operates primarily (but not necessarily) outside of conscious awareness. It is thought to rest on immediate sensory experiences associated with authorship for actions (sense of agency, i.e. the experience of initiating and controlling bodily movement and physiological states) and 'mineness' of the body (sense of body ownership). The 'acting' self and the associated sense of agency, 
certainly plays an important role in shaping the 'bodily self'. However, research on embodied self-awareness in the domain of action cognition is extensive and beyond the scope of our purpose here. Instead, this chapter will primarily explore representations of the bodily self in relation to affective touch.

What kinds of body representations do exist? Scientific research seems to suggest that there are "many bodies in the brain". Neuroimaging studies have found different cortical regions specialized for different facets of bodily awareness, with the strongest evidence for the posterior parietal cortex, the anterior insula and the extrastriate body area (for a review, see Berlucchi \& Aglioti, 2010). Moreover, many different conceptualizations have been proposed in an attempt to classify the various forms and sub-components of mental body representations (Berlucchi \& Aglioti, 1997; Dijkerman \& de Haan, 2007; Gallagher, 2005). Most of these concepts, however, have been used rather vaguely or inconsistently across studies. This has contributed to partly divergent interpretations of research findings, which has led to much debate regarding their usefulness for understanding bodily self-awareness (see, Berlucchi \& Aglioti, 2010). Of particular controversy is the classical dichotomous distinction between the concepts of 'body schema' and 'body image', which have been used by different authors in partly opposite ways (Gallagher, 2005). The body schema has been defined by most authors to exclusively rely on proprioceptive input from muscles, tendons and joins and to provide the postural, kinaesthetic and tactile basis for sensorimotor capacities underlying action. The body image, in contrast, has mostly been referred to as the visual representation of the body as it appears from the outside, as an object in third person perspective, including the shape and length of limbs. It has often been used in relation to more declarative kinds of body-related knowledge, and to contribute to a sense of body ownership and self-consciousness. Other alternative proposals that have been put forward distinguish between online (momentary) vs. offline (continuous) representations of the body 
(e.g., Carruthers, 2008), or suggest a multi-component / multi-level organization (e.g., Giummarra, Gibson, Georgiou-Karistianis, \& Bradshaw, 2008).

For the present purposes, in order to elude conceptual vagueness, the structure of the chapter will not be based on distinct concepts of the bodily self, but we will focus more specifically on the experimental paradigms that have been used to study body representation. The terms bodily self or bodily self-awareness will be used here to refer generally to the implicit or explicit knowledge one may have of oneself as a bodily whole and of being localized within the bodily borders. The term body representation will be used to refer to a mental representation of the body that emerges from an integration of multiple sensorimotor signals and therefore is dissociable from the primary sensory representations.

\subsection{The Role of Interoception in the Bodily Self}

It has long been proposed that bodily self-consciousness relies on an integrated representation of multiple streams of sensory information, although findings are not fully consistent with respect to the precise weighing of the various sensory cues (Craig, 2009; Critchley, Wiens, Rotshtein, Ohman, \& Dolan, 2004; Seth, Suzuki, \& Critchley, 2011). Indeed, despite the important role of interoceptive signals for bodily self-awareness, scientific work has focused almost exclusively on the integration of exteroceptive signals. Visceral afferent signals have long been neglected in this empirical and theoretical picture of body representation. Only recently has empirical research revealed and emphasized the importance of interoceptive (Craig, 2002; Seth et al., 2011), emotional (Damasio, 1999) and social (Prinz, 2012) mechanisms underpinning bodily self-awareness.

Specifically, it has been proposed that interoception, the perception of the body from within, lies at the core of selfhood (Craig, 2009; Critchley et al., 2004; Damasio, 1999). 
Interoception refers to the perception of the physiological condition of the body. It is thought to rest on a separate specialized interoceptive system that is associated with the autonomic nervous system and has been related to the generation of subjective feelings and selfawareness (Craig, 2009; Critchley et al., 2004; Damasio, 2010; Seth et al., 2011). Interoception involves representations from multiple modalities such as temperature, itch, pain, cardiac signals, respiration, hunger, thirst, pleasure from sensual touch and other bodily feelings. It is distinct from the exteroceptive system, which refers to the classical sensory modalities for perceiving the external environment as well as proprioceptive and kinesthetic input informing about the movement of the body in space (Blanke \& Metzinger, 2009; Craig, 2003; Critchley et al., 2004).

The mental representation of the internal physiological state of the body, such as the awareness of one's bodily pain or, heartbeat, has been associated with the insular cortex (Craig, 2002, 2009; Critchley et al., 2004). More specifically, the dorsal posterior insula supports primary cortical representations of ascending interoceptive pathways reporting physiological states (e.g., mechanical, thermal, or chemical) of skin, muscles, joints and internal organs (Craig, 2003). The posterior insula also serves as the primary cortical area for projections of unmyelinated C-tactile (CT) afferents responding to gentle touch (Morrison, Bjornsdotter, \& Olausson, 2011; Olausson et al., 2002; Olausson et al., 2008). These primary interoceptive representations are then re-represented and integrated with exteroceptive signals in mid-anterior portions of the insular cortex, where interoceptive awareness and bodily selfawareness is thought to emerge (Craig, 2009).

Apart from interoceptive modalities such as pain and itch that can be assessed by stimulating nerve endings on the skin, there are different 'objective' methods for assessing the perception of 'visceral' interoception such as gastrointestinal distension, adrenergic stimulation, and heartbeat perception. However, most attempts to quantify individual 
differences in the ability to perceive one's own internal bodily states have predominantly focused on cardiac activity perception. In heartbeat perception tasks participants are asked to detect and count their heartbeat silently under resting conditions (Pollatos \& Schandry, 2004; Schandry, 1981). Quite stable inter-individual, trait-like differences were found in these tasks in a plethora of studies (for review see, Pollatos, Kirsch, \& Schandry, 2005). The perception of cardiac signals, therefore, has been proposed as a measure of "interoceptive awareness".

Importantly, there is preliminary evidence that such measures of cardiac interoceptive awareness shape various body representations. In a series of studies on the sense of body ownership, Tsakiris and colleagues found that participants with lower cardiac awareness were more susceptible to experimentally induced bodily illusions, such as the rubber hand illusion or the enfacement illusion (Tajadura-Jimenez, Longo, Coleman, \& Tsakiris, 2012; Tsakiris, Tajadura-Jimenez, \& Costantini, 2011). These illusions involve self-identification with another person's face or hand induced by synchronous visuo-tactile stimulation between the own and the other's face or hand (see also section 2.2 below). Other evidence showed that providing visual feedback of the physiological state of the body, such as cardio-visual feedback presented synchronously with the heartbeat of the participants, can enhance the sense of ownership for a virtual-hand (Suzuki, Garfinkel, Critchley, \& Seth, 2013), as well as self-identification with and self-location toward a virtual body (Aspell et al., 2013). Consistently with these studies in healthy volunteers, clinical studies in patients with disorders of body representation, such as somatoform and eating disorders have found reduced levels of interoceptive awareness, as perceived by heartbeat detection tasks (Mussgay, Klinkenberg, \& Ruddel, 1999; Pollatos et al., 2008; Schaefer, Egloff, \& Witthoft, 2012; see also section 3). Conversely, improvements in cardiac awareness have been linked with reduction of distress associated with somatic symptoms in these disorders (Schaefer, Egloff, Gerlach, \& Witthoft, 2014). 
However, the relation between such measures of cardiac awareness and the perception of signals from other interoceptive modalities remains to be specified, and further explored in relation to multisensory integration and the bodily self. In the meanwhile, indirect support for the more general role of cardiac awareness in the bodily self can be found in the observed relation between cardiac, interoceptive awareness and emotion. For example, recent studies using heartbeat perception tasks have showed that cardiac awareness is positively correlated with the perceived intensity of emotional stimuli (Critchley et al., 2004; Pollatos et al., 2005). Clinical studies have also pointed to fact that patients with anxiety disorders have an higher interoceptive awareness (Domschke, Stevens, Pfleiderer, \& Gerlach, 2010; Dunn et al., 2010; Pollatos, Traut-Mattausch, \& Schandry, 2009; Stevens et al., 2011), while patients with depression typically show reduced cardiac awareness (Pollatos et al., 2009). These findings bring us to the relation between interoception, emotion and the bodily self which will be considered in the following section.

\subsection{The Role of Emotion in the Bodily Self}

The idea that bodily self-awareness is tied to signals that are important for homeostatic regulation has commonalities with theories that emphasize the perception of physiological, bodily states as the basis of emotion (Damasio, 1994, 1999; James, 1884, 1890). The precise role of bodily perception however, in relation to emotion and cognition is a classical (for review, see, Sander, 2013) and ongoing debate (Critchley et al., 2004; Niedenthal, 2007; Seth, 2013) that escapes the scope of this article. Here we refer merely to the relation between emotional awareness and certain sensory modalities as a prelude to our consideration of affective touch and its role in the bodily self. 
The relation between emotion and body representation has been addressed in different sensory modalities. For example, paradigms involving visual bodily signals have revealed that body-selective cortical areas are modulated by emotional information and the socioeffective context in which the body is perceived (de Gelder et al., 2010; Van den Stock, Vandenbulcke, Sinke, \& de Gelder, 2014). These areas include the extrastriate body area (EBA; Downing, Jiang, Shuman, \& Kanwisher, 2001) and the fusiform body area (FBA; Peelen \& Downing, 2005), that are typically activated by images of body parts. Furthermore, a strong relation has been proposed to exist between emotion and vestibular body signals (for review, see Carmona, Holland, \& Harrison, 2009). The vestibular system plays an integral role in body ownership representation (Lenggenhager, Tadi, Metzinger, \& Blanke, 2007) and self-awareness (Simeon et al., 1997). The link to emotion is primarily based on the observation of a high comorbidity of vestibular dysfunctions and psychiatric symptoms such as anxiety, depression and panic disorders (e.g., Balaban \& Thayer, 2001; Gazzola et al., 2009; Godemann, Linden, Neu, Heipp, \& Dorr, 2004). Finally, abundant examples for a strong interrelation between emotional disturbances and somatic symptoms can be observed in neuropsychiatric disorders. This relation is perhaps most obvious in conditions such as body integrity identity disorder (BIID; Sedda, 2011) or misoplegia (Critchley, 1974), in which patients report extreme dislike of and other strong, negative emotions towards an individual body part, even to the degree that they may wish that it is amputated. Moreover, the excessive preoccupation with body size and the perceptual overestimation of one's own actual body size in patients with eating disorders involves a strong negative emotional attitude towards the body. We consider examples of these pathologies and discuss the potential role of affective touch in the third section of the present chapter.

Strong effects of emotion have also been observed in the processing of nociceptive body-related signals. The affective modulation of pain has been examined at the spinal and 
cerebral levels and evidence was found for hyperalgesic and analgesic effects of negative and positive emotions, respectively (Duquette, Roy, Lepore, Peretz, \& Rainville, 2007; Rainville, Bao, \& Chretien, 2005). In a recent study, for example, emotions induced by pleasant and unpleasant images modulated spinal nociceptive responses to painful electrical stimulation and pain perception (Roy, Piche, Chen, Peretz, \& Rainville, 2009). The modulations of perceived pain were particularly correlated with activity in the right anterior insula, while a partially distinct brain circuit was involved in the modulation of spinal nociceptive responses. Interestingly, the anterior insula has been shown to code the affective component of pain (Kong et al., 2006; Schreckenberger et al., 2005), and it has been found to be sensitive to other emotional experiences associated with odors (Royet, Plailly, Delon-Martin, Kareken, \& Segebarth, 2003) and tastes (Small et al., 2003). These observations are consistent with current theoretical models proposing a dominant role of the anterior insula in both bodily (e.g., Tsakiris, Hesse, Boy, Haggard, \& Fink, 2007) and emotional awareness (Critchley et al., 2004).

\section{AFFECTIVE TOUCH \& THE BODILY SELF}

\subsection{Touch and the Elusive Dualities of the Body}

How does affiliative touch contribute to the bodily self? Which particular sensory, affective and interpersonal features convey relevant information for the construction of a sense of embodied selfhood? It appears that when we are touched at the physical boundary of the body, that is the skin, our brain forms two sets of partly independent representations about this single experience. On the one hand, the tactile stimulus is processed in terms of its 
exteroceptive, discriminatory processes in classical peripheral pathways and somatosensory cortical areas, while on the other hand, a specialized peripheral and central system seems to code for the affective properties of the same stimulus. Indeed, the recent neurophysiological evidence that is reviewed in this book suggests the existence of a dual touch system consisting of two parallel neural pathways: one for purely sensory touch, composed of skin mechanoreceptors projecting to the thalamus and primary somatosensory cortex (Johnson \& Hsiao, 1992), and another for affective touch (Olausson et al., 2002; Vallbo, Olausson, \& Wessberg, 1999). The affective touch system is thought to rely on a distinct subgroup of mechanoreceptors, tactile C-fibres, responding only to slow (between 1-10 cm/s), caress-like touch, with activation being correlated with pleasantness ratings on visual-analogue scales (Löken, Wessberg, Morrison, McGlone, \& Olausson, 2009). What is more, C-tactile afferents take a distinct ascending pathway from the periphery to a different part of the thalamus and then to the posterior insular cortex (Morrison et al., 2011; Olausson et al., 2002). As aforementioned, the latter pathway is considered as mediating an early convergence of sensory and affective signals about the body, which are then re-represented in the mid and anterior insula: the proposed sites of interoceptive awareness (Craig, 2009; Critchley et al., 2004).

This duality at the neurocognitive level seems to lead to a number of psychological dualities at the core of our embodied self-consciousness. In this section, we will highlight two such dualities, namely the inside-outside and the self-other distinctions, and describe their elusive and interrelated character, as well as certain conceptual fallacies associated with them. In the following sections, we review research that has focused on how affective touch may be integrated with other sensory and motor modalities to shape our bodily self.

\subsubsection{The Inside-Outside Distinction}


Affective touch such as a caress is applies at the outer surface and boundary of the body, namely the skin. As aforementioned however, the signals conveyed via such dynamic, gentle touch provide information about both the internal state of the organism ('this experience feels good') and the external surface of the body (e.g., 'I am touched at right forearm'). This multiplicity of information and pathways poses conceptual challenges for any rigid, dichotomous distinction at the level of awareness between sensation and emotion, interoception and exteroception, or, inner and outer body, or, body schema and body image. Since Sherrington, neuroanatomy categorizes senses into interoception, exteroception and proprioception. Recently affective touch and pain were reclassified as interoceptive modalities (Craig, 2003), given their aforementioned neurophysiological specificity and role in providing information about the physiological stability of the body (homeostasis). Yet unlike other interoceptive modalities, affective touch, itch and cutaneous pain are by definition linked with external stimuli (and frequently social agents, see below) and are applied on the outer surface of the body. It thus appears that such modalities may act as important mediators of the bodily inside and outside, possibly having a unique contribution to the coherent and unified character of body awareness (see section 2.2).

\subsubsection{The Self-Other Distinction}

Affective touch seems to simultaneously capture information about 'the self' and the outside world, in the same way that it transcends the inner-outer body distinction. Specifically, gentle, slow stimulation of the skin provides information about one's own body (as described above), as well as about the external world (e.g., 'this is a soft material, moving slowly'). Importantly, research has now shown that the perception of affective touch can provide information about the emotions and thoughts of other individuals (Hertenstein, Keltner, App, Bulleit, \& Jaskolka, 2006; Hertenstein, Verkamp, Kerestes, \& Holmes, 2006). 
We speculate that this rather unique, parallel activation of pathways relating to the internal representation of the body, as well as the external, social world, presumably acts as an early, developmental source of bodily information regarding the self-other distinction. Indeed, contrary to traditional assumptions, seminar studies in developmental psychology have established that even before their first birthday infants show unequivocal signs of primary self-other distinction and corresponding social interaction behaviours; they actively solicit their caregivers' attention and engage themselves in interactive practices that are attuned to the actions and gestures of other humans (for recent reviews see, Braten \& Trevarthen, 2007; Fonagy, Gergely, Jurist, \& Target, 2004; Meltzoff \& Brooks, 2001; Reddy, 2008; Rochat, 2009; Trevarthen, 1993). There is already some evidence from developmental psychology suggesting that multisensory integration, including the integration of tactile stimuli with vision and proprioception, contributes to the establishment of the psychological distinction between one's body and that of others (Cascio, Foss-Feig, Burnette, Heacock, \& Cosby, 2012). We speculate that given its dual, sensory-discriminatory and affective-motivational nature, social touch, an essential part of early mother-infant interactions, has a unique developmental role in establishing the physical boundaries of the psychological self.

\subsubsection{The Self-Other Relation}

Somewhat paradoxically, affective touch may be important not only in establishing and maintaining a healthy self-other distinction but also in mediating the psychological connection between self and other and related social cognition abilities (for the so-called ‘social touch’ hypothesis; Morrison, Loken, \& Olausson, 2010; Olausson et al., 2008). Seminar studies have established that humans, a species unique in their need for early nurturance and care by conspecifics, have developed an innate social attachment drive, unrelated to hunger or thermoregulation, and a corresponding lifelong need for social 
connection (Bowlby, 1969; Harlow, 1958; Panksepp, 1998). Perhaps built upon the evolutionary foundations of grooming (Dunbar \& Shultz, 2007) and tickling (Panksepp \& Burgdorf, 2003) behaviours in other mammals, human tactile contact in early life is increasingly understood to be central to a healthy, emotional development (cf, Fogel, 2013; Prinz, 2012; Winnicott, 1971). For instance, self-reported frequency of maternal stroking over the first weeks of life has been associated with reduced association between prenatal depression and adverse mental health outcomes in infancy (e.g., Arditi, Feldman, \& Eidelman, 2006; e.g., Dieter, Field, Hernandez-Reif, Emory, \& Redzepi, 2003; see also, Sharp et al., 2012).

Similarly, the physical development of premature infants can benefit from skin-toskin contact with caregivers (e.g., Dieter et al., 2003). It has been suggested that a decrease in cortisol levels, and stimulation of oxytocin and growth hormones underlie these touch effects (Field, 2001). 'Kangaroo care' (KC) is by now a common intervention in neonatal care in many clinics with increased emergence of evidence-based KC guidelines (DiMenna, 2006). $\mathrm{KC}$ allows the naked infant to have direct tactile contact with the parent's bare chest and to hear the parent's heartbeat. It has been shown to significantly reduce pain behaviour in fullterm infants and stable preterm infants (for review, Warnock et al., 2010). Other evidence has shown that skin-to-skin contact following Caesarean section may help maintain temperature of new-borns and reducing new-born stress (for review, Stevens, Schmied, Burns, \& Dahlen, 2014). More generally, being held and gently stroked by caregivers is also associated with reduced pain and distress in infants (Esposito et al., 2013; Gray, Watt, \& Blass, 2000; PelaezNogueras, Field, Hossain, \& Pickens, 1996).

Moreover, these developmental effects seem to be mirrored by life-long phenomena. Tactile interactions with significant others can help in regulating emotions, for example, in stressful or threatening contexts (Coan, Schaefer, \& Davidson, 2006; Gallace \& Spence, 
2010). A number of studies in healthy adults have demonstrated that warm, social, physical contact among couples can lead to decreases in blood pressure reactivity and cortisol release to stress (Ditzen et al., 2007; Grewen, Anderson, Girdler, \& Light, 2003), and can reduce physical pain (Krahe, Springer, Weinman, \& Fotopoulou, 2013). Recently, we have also found that the neuropeptide oxytocin, known for its role in social bonding and prosocial behavior, and its analgesic effects in animals ( $\mathrm{Gu} \& \mathrm{Yu}, 2007)$, can reduce pain perception in humans (Paloyelis, Krahe, Howard, Williams, \& Fotopoulou, submitted).

More generally, such findings are consistent with the crucial role of grooming behaviours in mammals, particularly as regards the formation of social bonds and the development of life-long healthy resilience to environmental threat and bodily pain (for review see, Panksepp, 1998). For example, early postnatal maternal tactile stimulation in rats can modify prenatal adverse effects by reducing HPA axis reactivity to bodily stressors (Vallee et al., 1999) and increased postnatal sensory input from maternal care reduces excitation to stress-responsive hypothalamic neurons and even has beneficial epigenetic effects (Korosi et al., 2010).

In addition, recent neuroimaging studies have shown that neural regions such as the posterior superior temporal sulcus (STS) and the medial prefrontal cortex that are typically associated with the 'social brain' and a number of social cognition abilities, such as perspective taking and mind-reading, are selectively engaged by the processing of affective touch (Bennett, Bolling, Anderson, Pelphrey, \& Kaiser, 2014; Bjornsdotter, Gordon, Pelphrey, Olausson, \& Kaiser, 2014; Gordon et al., 2013). Interestingly, there is at least a female-specific developmental increase in the sensitivity of the posterior STS to affective touch (Bjornsdotter et al., 2014).

Although some of the above brain areas are also linked with self-related processing and embodied facets of perspective taking (Decety \& Jackson, 2004), to our knowledge, few 
systematic, developmental studies have focused on the role of affective touch in the formation of the bodily self. Yet indirect confirmation comes from studies on neurodevelopment in low birth weight infants (see also, Gallace \& Spence, 2010). For example, Weiss and colleagues (2004) observed that infants of mothers who used more stimulating touch during feeding at 3 months had better visual-motor skills and more advanced gross motor development. Finally, the research application of multisensory integration paradigms to infant body perception (Cowie, Makin, \& Bremner, 2013; Filippetti, Johnson, Lloyd-Fox, Dragovic, \& Farroni, 2013) suggests that the specific, developmental role of affective, social touch can soon be studied in early infancy and childhood. In one of these studies, multisensory integration of visuo-tactile and proprioceptive information did not lead to changes in the bodily self in children with Autism Spectrum Disorders (ASD) as fast as it did in children without ASD. Moreover, this effect was moderated by individual differences in social cognition abilities such as empathy, in the sense that higher levels of empathy were associated with greater changes in body representation following multisensory integration. These findings point to the tight link between attuned, social responses to infants' bodily needs and the development of both self- and other-related cognition.

\subsection{How Touch Structures Body Representation}

Before discussing the specific link between affective touch and the bodily self, we will briefly discuss the general dimension of touch in relation to body representation in order to better understand and integrate its affective aspects. Evidence for the general influence of tactile afferent signals and their reciprocal interaction with mental body representations has been provided by a range of different research paradigms (for review, see, Serino \& Haggard, 2010). In these paradigms, most attention has been focused on the sensory discriminative component of touch. 
One important piece of evidence for the impact of tactile information on body representation comes from the rubber hand illusion (RHI) in healthy participants (Botvinick \& Cohen, 1998). Observing a rubber hand being stroked and at the same time experiencing one's own unseen hand being stroked in synchrony typically elicits the sensation that the rubber hand is one's own hand. It was concluded that the concurrence of primary tactile and visual input strongly influences the incorporation of body parts within the psychological self. Other multisensory integration paradigms have observed changes in the bodily self in relation to isolated body parts such as fingers (Dieguez, Mercier, Newby, \& Blanke, 2009), arms (Fourneret \& Jeannerod, 1998), and the face (Sforza, Bufalari, Haggard, \& Aglioti, 2010), or even the perception of the entire body (Ehrsson, 2007; Lenggenhager et al., 2007). Other studies were able to induce the rubber hand illusion even when vision was not implicated, in the so-called 'somatic' rubber hand paradigm (Ehrsson, Holmes, \& Passingham, 2005). Specifically, when blindfolded participants applied externally-guided touch to an artificial hand and synchronously received touch on their own hand from the experimenter, they experienced the illusion that they were touching their own hand. This was observed even when they received incongruent visual feedback (White, Aimola Davies, Halleen, \& Davies, 2010). That is, a match between touch and proprioception (i.e., active and passive touch) was shown to be sufficient to induce or change feelings of ownership for the artificial hand, as reflected in the illusion of self-touch.

Another important domain of touch that has been repeatedly shown to modify the structural representation of the body as a physical object is self-touch. In fact, phenomenological philosophy considers self-touch a basic form of self-awareness based on the integration of active and passive hand (Husserl, 1989; Merleau-Ponty, 1962). For example, Schütz-Bosbach and colleagues asked participants to touch several fingers of one hand with fingers of the other hand (2009). By interleaving the experimenter's fingers with 
the fingers of the participant's passive hand they induced a discrepancy between the number of fingers touched on the active and passive hand. It was found that participants underestimated the number of fingers specifically in the self-touch conditions. These findings suggest that self-touch may influences the mental representation of body parts, in particular via somatic inputs (i.e., the passive experience of being touched) rather than sensorimotor signals associated with active aspect of touch.

A number of neuropsychological studies have investigated the influence of activeand self-touch on the processing of somatosensory signals and the structural representation of the body in relevant pathologies. Patients with right hemisphere lesions may suffer from severe loss of sensory function resulting in the inability to detect sensory stimulation administered to the affected limb. Importantly, in these patients is has been found that selftouch can enhance sensory processing and improve tactile detection (Valentini, Kischka, \& Halligan, 2008; Weiskrantz \& Zhang, 1987). In addition to this low-level sensory enhancement, beneficial effects of self-touch have also been reported in relation to higher order body representations such as body ownership. For example, White and colleagues (2011) used the somatic rubber hand paradigm (Ehrsson et al., 2005) to investigate whether self-touch enhancement can be observed even when the patient is unable to use knowledge about the position of the limb. The patient's affected hand was stimulated, while the unaffected hand was guided by the experimenter to stimulate a prosthetic hand. If these two events were executed simultaneously, enhanced detection of the sensory stimulation was observed in the patient's affected hand. Since no visual or proprioceptive information was available to patients, it can be concluded that self-touch allowed them to feel rather than infer the tactile stimulation.

A recent study by Kammers et al. (2010) is important because it explicitly investigated the role of touch and body representation in relation to emotions. They induced 
an illusory feeling of painful heat in the middle finger by placing the participant's index and ring finger in hot water, and the middle finger in cold water ('thermal grill illusion'). This illusion has traditionally been explained by low-level interactions and disinhibition of $\mathrm{C}$ fibers signaling pain. The authors found that the perceived heat was reduced if the same fingers of the unstimulated hand touched the three corresponding fingers immediately after the stimulation. This suggests that self-touch may gate strongly negative affective signals and increase the coherence of the mental representation of the body. Moreover, it has been shown that touch is associated with changes in autonomic bodily functions, such as reductions in heart rate, blood pressure and hormone secretion (Ditzen et al., 2007; Grewen et al., 2003).

The important conclusion from the above reviewed evidence is that touch is a crucial factor contributing to mental body representation via its purely sensory-discriminatory component. Given this evidence and the role of emotions for the bodily self, it is reasonable to assume a specific influence of the purely affective and social components of touch on body representation, which will be discussed in the following section.

Figure 1 illustrates the various ways by which social, emotional touch experience may interrelate with the bodily-self.

\#\#\# Figure 1 about here \#\#\#

\subsection{Affective Touch Modulates the Sense of Body Ownership}

As we outlined above, most experimental research on the bodily self has thus far explored how the integration of exteroceptive and proprioceptive signals may give rise to changes in the habitual sense of body ownership (for review see, Tsakiris, 2010). By contrast, remarkably little attention has been paid to how the sense of body ownership can be modulated by interoceptive signals arising from the body itself. Previous research has shown 
that individuals who score lower on a trait measure of interoceptive sensitivity (the heart beat detection task, described previously) experience a stronger rubber hand illusion (RHI) compared to individuals who score higher on the same measure (Tsakiris et al., 2011). In addition, physiological regulation (e.g., temperature) of the body during the illusion can be influenced by exteroceptive, multisensory integration (Moseley et al., 2008). However, Schütz-Bosbach et al. (2009) found no effect of using materials with different qualities (i.e. soft vs. rough) on body ownership during the RHI.

A recent study by Suzuki and colleagues (2013) specifically examined the role of interoception and exteroception on body ownership, by presenting cardio-visual feedback in time with the participant's heartbeat. This feedback enhanced ownership of a virtual hand, indicating that online integration of interoceptive and exteroceptive signals can modulate the sense of body ownership. Similar findings have been confirmed by other studies Aspell and colleagues (2013), who showed that cardio-visual signals modulate not only the sense of body ownership, but also tactile perception. These recent data suggest that the integration of internal and external body signals is crucial for self-consciousness (Aspell et al., 2013). However, none of these studies have examined how affective (pleasant) touch, which provides a unique and direct source of interoceptive information about the state of the body, influences body ownership.

In light of the above, we examined body ownership during a RHI procedure that used different stroking speeds to deliver either pleasant $(3 \mathrm{~cm} / \mathrm{s})$ or affectively neutral $(18 \mathrm{~cm} / \mathrm{s})$ touch to participants' forearms (Crucianelli, Metcalf, Fotopoulou, \& Jenkinson, 2013). Our results confirmed that slow touch on hairy skin is perceived as more pleasant than fast touch (Löken et al., 2009, Fig. 1a), and, more importantly, demonstrated for the first time that pleasant touch produces higher levels of subjective body ownership feelings and sensations (Figure 2b). 


\section{\#\#\# Figure 2 about here \#\#\#}

Our findings were later confirmed by Lloyd et al. (2013), who also found that slow, caress-like touch, modulated subjective reports of pleasantness and body ownership during the RHI. Interestingly, Lloyd and colleagues found that stroking the palm of the hand (which contains no CT afferents, also elicited greater feelings of pleasantness and enhanced embodiment. This suggests that the perceived pleasantness of touch and its effect on embodiment may be mediated by a complex interaction of psychological and neural mechanisms, which goes beyond the simple activation of skin fibres. Further evidence of this complexity can be found in the most recent study to examine the effect of affective touch on body ownership (van Stralen et al., 2014). Unlike previous studies (Crucianelli et al., 2013; Lloyd et al., 2013), van Stralen and colleagues found that pleasant touch did not affect subjective measures of body ownership (i.e. questionnaires), but did influence the perceived location of the real hand in relation to the rubber hand (i.e. the so-called proprioceptive drift). Contrary to Lloyd et al. (2013), this effect was specific to the use of a C-tactile optimal velocity applied to hairy skin. According to van Stralen and colleagues, these results suggest that C-tactile fibres modulate body representation in terms of multisensory integration, rather than being involved in the conscious experience of body ownership. However, further studies are needed to fully explain these contradictory findings and determine the precise mechanisms by which affective touch modulates body ownership.

For example, it is currently unknown whether there are individual differences in pleasant touch perception, and whether such differences might depend only on C-tactile stimulation. Moreover, to the extent that pleasant touch (Bermudez, 2005; Bjornsdotter, Loken, Olausson, Vallbo, \& Wessberg, 2009) and other interoceptive modalities such as pain (Krahe et al., 2013) are thought to convey important social signals of safety versus threat, 
future studies are needed that investigate the potential role of social, affiliative signals on the sense of body ownership and more generally, the malleability of the bodily self.

\section{THE ROLE OF TOUCH IN PATHOLOGICAL BODILY AWARENESS}

\subsection{The Role of Touch in General Mental Health}

Affective touch seems to promote psychological and physical well-being. In this third part of the chapter, we will first briefly outline accumulating clinical and experimental evidence for the beneficial role of affective touch in healthy individuals, before focusing on psychiatric and neurological disorders that have been specifically linked with abnormalities in the bodily self. These disorders involve severe forms of dysfunctional and impaired body representation and are also assumed to have a significant socio-emotional component determining the development and severity of pathology. Therefore, gentle, caressing touch may potentially be an important remedy to these disorders.

Several studies have reported health benefits of light touch on a number of bodily conditions and autonomic functions such as blood pressure and heart rate, which have been taken to suggest enhanced parasympathetic nervous system activity and embodied selfawareness (see, Fogel, 2013). For example, clinical trials demonstrated beneficial effects of soft, interpersonal touch on bodily symptoms such as pain in fibromyalgia syndrome (Denison, 2004), headache pain (Keller \& Bzdek, 1986), pain and sensory symptoms associated with neuropathy or degenerative joint diseases (Blankfield, Sulzmann, Fradley, Tapolyai, \& Zyzanski, 2001; Gordon, Merenstein, D'Amico, \& Hudgens, 1998), and on agitation in Alzheimer patients (Woods, Craven, \& Whitney, 2005; Woods \& Dimond, 
2002). These therapeutic touch interventions typically involve light touch, rather than massaging movements, which is applied to the tense or painful area of the body (for review see, Kerr, Wasserman, \& Moore, 2007). Often they are coupled with attentional practices used in meditative traditions such as mindfulness meditation. Most of these studies, however, did not explicitly measure subjective bodily self-awareness or related neural markers, therefore, the exact pathways mediating the effects of this type of therapeutic touch are still unclear. It has been argued that touch activates the parasympathetic nervous and embodied self-awareness, which in turn reduces pain and supports restoration (see, Fogel, 2013). Other findings support benefits of massage therapy for bodily self-awareness in eating disorders, by decreasing body dissatisfaction and levels of stress as reflected in lower cortisol (stress) hormone levels (Hart et al., 2001). In the following section we discuss the specific relation between anorexia nervosa and interpersonal, affective touch.

\subsection{Affective Touch and Body Image Disturbances in Anorexia Nervosa}

Disturbances in body representation and awareness are a core, clinical features in anorexia nervosa (AN), an eating disorder with unknown aetiology and the highest rate of mortality among all psychiatric disorders (Sullivan, 1995). Patients with AN show restricted eating, an endless pursuit of idealized levels of thinness irrespective of actual body mass index, and obsessive fears of becoming fat (Wagner et al., 2008). Given these clinical traits, a large number of studies have investigated whether patients with AN are dissatisfied with their own body, show any other negative attitudes towards it, or overestimate their weight and shape. Such attitudes and tendencies are typically described as 'body image' disturbances. Several investigations and meta-analyses have claimed that such disturbances are mostly attitudinal and emotional, and do not entail low-level, perceptual deficits, such as body size 
overestimation (Cash \& Deagle, 1997; Cornelissen, Johns, \& Tovee, 2013; Farrell, Lee, \& Shafran, 2005; Smeets, Smit, Panhuysen, \& Ingleby, 1998).

Nevertheless, the possibility that AN is accompanied by abnormalities in low or higher-order perception of the body has recently captured the attention of cognitive neuroscientists. Accordingly, a number of perceptual tasks have been applied to AN samples, showing that AN patients overestimate their body size compared to healthy controls in visual, tactile and haptic perception (e.g., Grunwald et al., 2001; Guardia et al., 2012; Keizer et al., 2011; Urgesi et al., 2013), as well as in action-related tasks (Guardia et al., 2010; Nico et al., 2010). Furthermore, neuroimaging studies testing the visual perception of the body in patients with AN versus healthy controls have shown reduction of activation in middle occipitotemporal cortices, such as the extrastriate body area (EBA) and the fusiform body area (FBA), which are typically activated by viewing human bodies and body parts but not faces and objects (e.g., Suchan et al., 2010; Uher et al., 2005).

Interestingly, despite the clear clinical indications of abnormal emotional attitudes towards the body, as well as the more general emotional, abnormalities in AN patients, such studies on body perception have focused exclusively on the exteroceptive body, i.e. the body as perceived on the basis of classic sensations such as vision or sensory-discriminatory touch. Indeed, the so-called 'body image' disturbance in AN is understood as a separate domain of study than the amble investigations of reward motivation and anhedonia (inability to seek and enjoy pleasurable experiences) in AN (Friederich et al., 2006; Kaye, 2008; Soussignan, Schaal, Rigaud, Royet, \& Jiang, 2011; Tchanturia et al., 2012; Wagner et al., 2007). This separation of topics seems not only arbitrary, but it also portrays a dualistic distinction between perception and emotion or, body (perceived from the outside as an object) and mind (based on disembodied notions of emotional subjectivity). As we outlined above, sensations such as affective touch challenge such rigid dichotomies. They instead call for an embodied 
understanding of subjectivity that is grounded in the integration of bodily signals deriving from multiple 'internal' and 'external' sources.

To our knowledge it is only very recently that multisensory integration paradigms have been applied to the study of body awareness in AN. Specifically, Eshkevari and colleagues (2012) found that AN patients are more susceptible to the Rubber Hand Illusion (RHI, see above) than healthy female volunteers, even in the asynchronous tactile stimulation (control) condition. These suggested that there may be an increased sensitivity for visual aspects of body perception in AN patients. Keizer and colleagues (2014) have recently replicated this finding and also showed that the experience of ownership over the rubber hand, as well as the mere visual focus on the rubber hand in the asynchronous (control) condition, were able to reduce the prior overestimation of (own) hand width shown in the AN group. These results are consistent with prior findings in healthy volunteers showing that the incorporation of the rubber hand into the body representation affected the similarity that participants perceived between their own hand and the rubber hand, while the reverse was not true, i.e. objective similarity (as measured by skin luminance, hand shape, and third-person similarity ratings) did not appear to influence participants' experience of the RHI. Taken together, the above findings highlight that the bodily self is highly malleable in AN and also importantly suggest a direction of causality in the observed symptoms: it may be that the body image disturbances seen in AN patients are due to that abnormalities in the subjective sense of embodiment, rather than the other way around.

Interestingly however, none of the above studies have accounted for the role of interoception in the construction of the bodily self in AN. Apart from the aforementioned clinical reasons, this seems important as previous studies on AN have found altered subjective responses to interoceptive stimuli such as hunger and physical pain (e.g., Strigo et al., 2013) and a reduced capacity to accurately perceive one's heartbeat (Pollatos et al., 
2008). Therefore, in a recent study we investigated the idea that AN patients may present reduced bodily pleasure, by examining the perception of pleasant touch in AN. Healthy and AN participants were asked to rate the pleasantness of light touch applied to the forearm at CT-optimal (3 cm/s; pleasant) and non-CT optimal $(18 \mathrm{~cm} / \mathrm{s}$; neutral) velocities. Our preliminary data (Crucianelli, Cardi, Treasure, Jenkinson, \& Fotopoulou, In prep) reveal that AN participants rate the pleasantness of the perceived touch as lower in both slow and fast velocities compared to healthy controls. This suggests a generally reduced bodily pleasure in AN subjects and a potentially dysfunctional; remarkably the difference between patients and healthy controls seems to be significantly higher in the context of pleasant compared to neutral touch, suggesting a possible involvement of the-CT afferents system, or an abnormal cognitive regulation of this system. Interestingly however, our results also show that pleasant ratings were influenced by social manipulations in similar fashion in AN patients and controls. Thus these results indicate that perception of affective touch, rather than its social modulation maybe affected in AN. in the explanation of our results. These results are consistent with the more general social and emotional anhedonia in AN and corresponding hypotheses about the role of dopamine and other reward-related neural mechanisms in the aetiology of the disorder (Friederich et al., 2006; Kaye, 2008; Soussignan et al., 2011; Tchanturia et al., 2012; Wagner et al., 2007). The precise role of affective touch and other interoceptive, as well as social signals in the construction of the bodily self in AN remains to be specified. Nevertheless, as aforementioned, there are some preliminary indications that massage therapy can reduce AN symptomatology, including a decrease in body dissatisfaction and a corresponding increase in dopamine levels (Hart et al., 2001).

\subsection{Affective Touch and Body Disownership: Studies in Neuropsychological Disorders}


The body is normally omnipresent in the mind. As such, identifying the factors that constitute the bodily self is particularly problematic, because it is hard to achieve a viable 'control' condition in healthy volunteers where the bodily self is absent or subjective 'disembodiment' exists. In spite of the aforementioned progress in creating suitable, experimentally-induced sensorimotor conflicts and illusions, create convincing and stable states of disembodiment in healthy volunteers remains difficult (for discussion see, de Vignemont, 2011; Longo, Schuur, Kammers, Tsakiris, \& Haggard, 2008). By contrast, neurological patients with disorders of body awareness may show clear, counter-intuitive and long-lasting, subjective experiences of disembodiment. Indeed, there is some initial neural (Zeller, Gross, Bartsch, Johansen-Berg, \& Classen, 2011) and behavioural (Jenkinson, Haggard, Ferreira, \& Fotopoulou, 2013) evidence suggesting that the subjective sense of body disownership seen in these disorders is caused by damage to neural mechanisms that are separate from those involved in paradigms such as the Rubber Hand Illusion. In this sense, neurological disorders of body awareness represent unique windows of insight into the psychological and neural mechanisms of the bodily self.

Such disorders may affect different facets of the bodily self, including, among others, self-location and first-person perspective (autoscopic phenomena; Blanke, Landis, Spinelli, \& Seeck, 2004), body ownership (Vallar \& Ronchi, 2009) and motor agency and awareness (anarchic hand syndrome and anosognosia for hemiplegia; Fletcher \& Fotopoulou, in press; Fotopoulou, 2014). As in the case of studies with healthy volunteers, investigations of these disorders have mainly focused on the integration and representation of proprioceptive, vestibular and exteroceptive signals (vision and discriminatory touch). However, as evidence accumulated about the fundamental role of interoception in the bodily self in other fields (Craig, 2003; Damasio, 1999), a handful of neuropsychological studies have turned their attention to interoception. 
In this chapter, we review such studies with particular focus on one, prototypical disorder of body awareness: asomatognosia (from the Greek, meaning 'lack of body knowledge'). Asomatognosia refers to the lack of recognition of the existence or ownership of one's limbs (Jenkinson, Preston, \& Ellis, 2011). Patients may feel their contralesional arm is missing or they may perceive it as not belonging to themselves. The disorder also has several 'constructive' (positive in the 'Jacksonian' sense) variants. For example, patients may perceive their affected arm as belonging to someone else (somatoparaphrenia), as being duplicated (supernumerary phantom arm), or as having an identity of its own (personification). Direct confrontation by doctors does not improve awareness and, if anything, when patients are challenged they tend to become more ingrained in their false beliefs. Although such symptoms typically resolve spontaneously, they are of variable duration, lasting from days to years (Vallar \& Ronchi, 2009) and they constitute a considerable therapeutic challenge (Jenkinson et al., 2011).

Asomatognosia and its constructive variants (hereafter referred to as 'disturbance in the sense of body ownership', DSO, for brevity, see also Karnath, Baier, \& Nagele, 2005) typically occur in patients with right-hemisphere lesions (although left cases have been noted; see Vallar \& Ronchi, 2009). DSO is frequently associated with primary and higher-order motor, proprioceptive and tactile deficits. Nevertheless, these deficits do not seem sufficient for the occurrence of DSO, as primary sensorimotor loss and higher-order deficits such as neglect typically do not produce the awareness symptoms seen in these patients. Furthermore, tactile perception can be improved in DSO without a corresponding improvement in body ownership (Bottini, Bisiach, Sterzi, \& Vallar, 2002; Moro, Zampini, \& Aglioti, 2004) and patients retain their delusional beliefs about their affected arm even when this is placed in the non-neglected hemifield (Moro et al., 2004). 
Whether DSO should be considered a single disorder, and whether it is dissociable from motor, or sensory unawareness following right hemisphere lesions remain debated issues (e.g., compareInvernizzi et al., 2013; with Karnath \& Baier, 2010). Importantly, however, recent lesion mapping studies suggest that a number of brain regions associated with interoception and interoceptive salience may be selectively associated with DSO. Contrary to original assumptions about the role of the right premotor and parietal cortices in DSO, recent lesion mapping studies have revealed that right hemisphere areas such as the posterior insula, basal ganglia structures, certain limbic structures such as the amygdala and related subcortical white matter connections are selectively associated with DSO (Gandola et al., 2012; Invernizzi et al., 2013; Karnath et al., 2005; Zeller et al., 2011). Such areas and their connections have long been implicated in bodily salience, emotion and interoception, and as previously mentioned, the posterior insula has been critically implicated in the processing of primary affective touch signals.

Remarkably, however, only one systematic study has thus far focused on the role of interoception in DSO. Romano and colleagues (2014) measured anticipatory skin conductance responses to noxious, threatening stimuli approaching either the affected or the intact body side in patients with somatoparaphrenia. This was compared to a control group of patients with preserved ownership but decreased awareness of somatosensory deficit, and to a control group of patients with no deficits of ownership or sensory awareness. Anticipatory skin conductance responses for the disowned arm were selectively reduced in the somatoparaphrenic patients, but were intact in patients that showed clear deficits in tactile perception and related unawareness. These results point to a dissociation between (anticipatory) interoceptive awareness and awareness of discriminatory touch, and suggest that the sense of body ownership is tightly linked with the former and only to a lesser degree with the latter. To use the words of an asomatognosic patient reported long ago "But my eyes 
and my feelings don't agree, and I must believe my feelings. I know they [left arm and leg] look like mine, but I can feel they are not, and I can't believe my eyes." (C.W. Olsen, 1937, cited in Feinberg, 1997).

Motivated by a single case study that found that self-touch increased both the sense of ownership and positive feelings towards the paralyzed arm in a somatoparaphrenic patient (van Stralen, van Zandvoort, \& Dijkerman, 2011), we recently became interested in investigating the role of affective touch in DSO. We administered soft, light, dynamic tactile stimuli in CT-optimal speeds $(3 \mathrm{~cm} / \mathrm{s}$; known to elicit feelings of pleasantness) versus non CT-optimal, speeds (18cm/s; known not to elicit such feelings) to both arms of a group of seven patients with DSO, as well as ten control patients with similar lesions but intact sense of ownership for their affected arm. We measured their perception of pleasantness after each stroke, as well as patients' sense of body ownership for the touched arms before and after stimulation. Our preliminary findings suggest that patients with DSO have a disturbed CTbased affective touch system, in the sense that they do not seem to differentiate between the slow and fast speeds in their perception, and they seemed to rate both types of touch as more pleasant than the control group (see also previous section). Interestingly, however, we have noted that in most DSO patients, these touch trials have led to an increased sense of body ownership for the affected and previously, persistently-disowned arm. This study is on-going and the specificity, neural correlates and long-term effects of these manipulations remain to be tested. However, taken together the findings reviewed above provide preliminary indications that self- and other-touch that is experienced as pleasant and possibly linked with top-down, prior expectations of positive, supportive meanings, can enhance the sense of body ownership. This conclusion applies even in patients that have damage to brain areas critical for the processing of primary interoceptive signals. We may even speculate that it is precisely such impaired processing of primary interoceptive signals about the current state of the body 
that leads patients to adhere to past expectations of how the affected body parts should feel from the inside, leading to the ensuing aberrant beliefs about to whom the body parts belongs.

In sum, focusing on the role of affective touch in neurological disorders of higherorder body awareness may reveal unique aspects of the bodily self. In particular, such studies highlight the potential role of the touched skin as the interface upon which the categories of self and other, inside and outside, are constructed and maintained in the mind and brain.

\section{Concluding Remarks}

In this chapter, we highlighted behavioural and neuroimaging evidence that interpersonal touch - through its affective component - influences and selectively enhances the mental representation of our body. Critically, empirical research has shown that the bodily self relies on mechanisms of multisensory integration, and interoceptive signals have a unique role in such integration. This knowledge may be used to advance our understanding of the crucial role of social embodied communication in the aetiology of disorders such as anorexia nervosa, and may stimulate the integration of touch and mindfulness interventions as therapeutic strategies. Now that there is converging evidence for the interrelation between affective touch and the bodily self, a particularly important area for future research will be examining not only how affective touch influences each domain of body representation but also how it affects the interaction among the different domains of the bodily self, and how our ability to regulate our emotions might influence what sensory signals are used to inform our perception of our own body.

\section{Outstanding Question and Future Directions}


- Through what mechanisms do different emotional components of affective touch influence multisensory integration processes underlying body representation?

Emotion evoked or communicated by interpersonal affective touch has different components to it, including the emotional experience, motivational-behavioural tendencies, physiology reactions, and social meanings. It is unclear whether these components exert a dissociable impact on different aspects of the bodily self.

- $\quad$ Extensive research has been conducted on the role of motor action, in particular the sense of agency, for the minimal, embodied sense of self (see, Balconi, 2010). The sense of agency is the subjective experience of being the source, initiator and controller of my own bodily actions and through them events in the external world. Similar to sense of ownership, this aspect of the bodily self is thought to be shaped through interactions in social contexts (see, Prinz, 2012), in which our actions are influenced by others or aim at influencing others. This assumption, however, needs to be experimentally addressed, in particular with respect to the affective dimension of social interactions for which affective touch appears to be an ideal research approach.

- How does our ability or need to regulate emotion and the supporting role of others in this, influence our mental body representation and capacity for self-other distinction? Research has demonstrated that interpersonal contact influences emotion regulation, but investigation into how the regulation of valence or intensity of emotional experience affects the bodily self are in their infancy. Understanding the link between emotion regulation strategies, social communication and embodied self-awareness may shed light on psychopathologies associated with the bodily self.

\section{Acknowledgments}


The preparation of this chapter was supported by a European Research Council Starting Investigator Award' [ERC-2012-STG GA313755 to A.F.]. 


\section{References}

Arditi, H., Feldman, R., \& Eidelman, A. I. (2006). Effects of human contact and vagal regulation on pain reactivity and visual attention in newborns. Dev Psychobiol, 48(7), 561-573.

Aspell, J. E., Heydrich, L., Marillier, G., Lavanchy, T., Herbelin, B., \& Blanke, O. (2013). Turning body and self inside out: visualized heartbeats alter bodily self-consciousness and tactile perception. Psychol Sci, 24(12), 2445-2453.

Balaban, C. D., \& Thayer, J. F. (2001). Neurological bases for balance-anxiety links. J Anxiety Disord, 15(1-2), 53-79.

Balconi, M. (2010). Neuropsychology of the Sense of Agency. From Consciousness to Action. Milan: Springer.

Bennett, R. H., Bolling, D. Z., Anderson, L. C., Pelphrey, K. A., \& Kaiser, M. D. (2014). fNIRS detects temporal lobe response to affective touch. Soc Cogn Affect Neurosci, 9(4), 470-476. doi: $10.1093 /$ scan $/$ nst008

Berlucchi, G., \& Aglioti, S. (1997). The body in the brain: neural bases of corporeal awareness. Trends Neurosci, 20(12), 560-564.

Berlucchi, G., \& Aglioti, S. M. (2010). The body in the brain revisited. Exp Brain Res, 200(1), 25-35.

Bermudez, J. L. (2005). The phenomenology of bodily awareness. In D. Woodruff Smith \& A. L. Thomasson (Eds.), Phenomenology and philosophy of mind (pp. 295-322). Oxford: Clarendon Press.

Bjornsdotter, M., Gordon, I., Pelphrey, K. A., Olausson, H., \& Kaiser, M. D. (2014). Development of brain mechanisms for processing affective touch. Front Behav Neurosci, 8, 24. doi: 10.3389/fnbeh.2014.00024

Bjornsdotter, M., Loken, L., Olausson, H., Vallbo, A., \& Wessberg, J. (2009). Somatotopic organization of gentle touch processing in the posterior insular cortex. J Neurosci, 29(29), 9314-9320.

Blanke, O. (2012). Multisensory brain mechanisms of bodily self-consciousness. Nat Rev Neurosci, 13(8), 556-571. doi: 10.1038/nrn3292

Blanke, O., Landis, T., Spinelli, L., \& Seeck, M. (2004). Out-of-body experience and autoscopy of neurological origin. Brain, 127(Pt 2), 243-258. doi: 10.1093/brain/awh040

Blanke, O., \& Metzinger, T. (2009). Full-body illusions and minimal phenomenal selfhood. Trends Cogn Sci, 13(1), 7-13. doi: 10.1016/j.tics.2008.10.003

Blankfield, R. P., Sulzmann, C., Fradley, L. G., Tapolyai, A. A., \& Zyzanski, S. J. (2001). Therapeutic touch in the treatment of carpal tunnel syndrome. J Am Board Fam Pract, 14(5), 335-342.

Bottini, G., Bisiach, E., Sterzi, R., \& Vallar, G. (2002). Feeling touches in someone else's hand. Neuroreport, 13(2), 249-252.

Botvinick, M., \& Cohen, J. (1998). Rubber hands 'feel' touch that eyes see. Nature, 391(6669), 756. doi: $10.1038 / 35784$

Bowlby, J. (1969). Attachment and loss: Vol. 1. Attachment. New York: Basic Books.

Braten, S., \& Trevarthen, C. (2007). Prologue: From infant intersubjectivity and participant movements to simulations and conversations in cultural common sense. In S. Braten (Ed.), On Being Moved: From Mirror Neurons to Empathy (pp. pp. 21-34). Amsterdam/Philadelphia: John Benjamins.

Carmona, J. E., Holland, A. K., \& Harrison, D. W. (2009). Extending the functional cerebral systems theory of emotion to the vestibular modality: a systematic and integrative approach. Psychol Bull, 135(2), 286-302. doi: 10.1037/a0014825

Carruthers, G. (2008). Types of body representation and the sense of embodiment. Conscious Cogn, 17(4), 1302-1316.

Cascio, C. J., Foss-Feig, J. H., Burnette, C. P., Heacock, J. L., \& Cosby, A. A. (2012). The rubber hand illusion in children with autism spectrum disorders: delayed influence of combined tactile and visual input on proprioception. Autism, 16(4), 406-419.

Cash, T. F., \& Deagle, E. A., 3rd. (1997). The nature and extent of body-image disturbances in anorexia nervosa and bulimia nervosa: a meta-analysis. Int J Eat Disord, 22(2), 107-125. 
Coan, J. A., Schaefer, H. S., \& Davidson, R. J. (2006). Lending a hand: social regulation of the neural response to threat. Psychol Sci, 17(12), 1032-1039. doi: 10.1111/j.1467-9280.2006.01832.x

Conway, M. A. (2001). Sensory-perceptual episodic memory and its context: autobiographical memory. Philos Trans R Soc Lond B Biol Sci, 356(1413), 1375-1384. doi: 10.1098/rstb.2001.0940

Cornelissen, P. L., Johns, A., \& Tovee, M. J. (2013). Body size over-estimation in women with anorexia nervosa is not qualitatively different from female controls. Body Image, 10(1), 103111. doi: 10.1016/j.bodyim.2012.09.003

Cowie, D., Makin, T. R., \& Bremner, A. J. (2013). Children's responses to the rubber-hand illusion reveal dissociable pathways in body representation. Psychol Sci, 24(5), 762-769.

Craig, A. D. (2002). How do you feel? Interoception: the sense of the physiological condition of the body. Nat Rev Neurosci, 3(8), 655-666. doi: 10.1038/nrn894

Craig, A. D. (2003). Interoception: the sense of the physiological condition of the body. Curr Opin Neurobiol, 13(4), 500-505.

Craig, A. D. (2009). How do you feel--now? The anterior insula and human awareness. Nat Rev Neurosci, 10(1), 59-70. doi: 10.1038/nrn2555

Critchley, H. D., Wiens, S., Rotshtein, P., Ohman, A., \& Dolan, R. J. (2004). Neural systems supporting interoceptive awareness. Nat Neurosci, 7(2), 189-195. doi: 10.1038/nn1176

Critchley, M. (1974). Misoplegia, or hatred of hemiplegia. Mt Sinai J Med, 41(1), 82-87.

Crucianelli, L., Cardi, V., Treasure, J., Jenkinson, P. M., \& Fotopoulou, A. (In prep). The perceptionof affective touch in anorexia nervosa.

Crucianelli, L., Metcalf, N. K., Fotopoulou, A. K., \& Jenkinson, P. M. (2013). Bodily pleasure matters: velocity of touch modulates body ownership during the rubber hand illusion. Front Psychol, 4, 703.

Damasio, A. R. (1994). Descartes' error: emotion, reason, and the human brain. New York: Avon.

Damasio, A. R. (1999). The Feeling of What Happens: Body and Emotion in the Making of Consciousness. San Diego: Harcourt.

Damasio, A. R. (2010). Self comes to mind. Constructing the conscious brain. London: Heineman.

de Gelder, B., Van den Stock, J., Meeren, H. K., Sinke, C. B., Kret, M. E., \& Tamietto, M. (2010). Standing up for the body. Recent progress in uncovering the networks involved in the perception of bodies and bodily expressions. Neurosci Biobehav Rev, 34(4), 513-527. doi: 10.1016/j.neubiorev.2009.10.008

de Vignemont, F. (2011). Embodiment, ownership and disownership. Conscious Cogn, 20(1), 82-93. doi: 10.1016/j.concog.2010.09.004

Decety, J. (2009). Empathy, sympathy and the perception of pain. Pain, 145(3), 365-366.

Decety, J., \& Jackson, P. L. (2004). The functional architecture of human empathy. Behav Cogn Neurosci Rev, 3(2), 71-100. doi: 10.1177/1534582304267187

Denison, B. (2004). Touch the pain away: new research on therapeutic touch and persons with fibromyalgia syndrome. Holist Nurs Pract, 18(3), 142-151.

Dieguez, S., Mercier, M. R., Newby, N., \& Blanke, O. (2009). Feeling numbness for someone else's finger. Curr Biol, 19(24), R1108-1109. doi: 10.1016/j.cub.2009.10.055

Dieter, J. N., Field, T., Hernandez-Reif, M., Emory, E. K., \& Redzepi, M. (2003). Stable preterm infants gain more weight and sleep less after five days of massage therapy. $J$ Pediatr Psychol, 28(6), 403-411.

Dijkerman, H. C., \& de Haan, E. H. (2007). Somatosensory processes subserving perception and action. Behav Brain Sci, 30(2), 189-201; discussion 201-139.

DiMenna, L. (2006). Considerations for implementation of a neonatal kangaroo care protocol. Neonatal Netw, 25(6), 405-412.

Ditzen, B., Neumann, I. D., Bodenmann, G., von Dawans, B., Turner, R. A., Ehlert, U., \& Heinrichs, M. (2007). Effects of different kinds of couple interaction on cortisol and heart rate responses to stress in women. Psychoneuroendocrinology, 32(5), 565-574. doi: 10.1016/j.psyneuen.2007.03.011

Domschke, K., Stevens, S., Pfleiderer, B., \& Gerlach, A. L. (2010). Interoceptive sensitivity in anxiety and anxiety disorders: an overview and integration of neurobiological findings. Clin Psychol Rev, 30(1), 1-11. doi: 10.1016/j.cpr.2009.08.008 
Downing, P. E., Jiang, Y., Shuman, M., \& Kanwisher, N. (2001). A cortical area selective for visual processing of the human body. Science, 293(5539), 2470-2473. doi: 10.1126/science.1063414

Dunbar, R. I., \& Shultz, S. (2007). Evolution in the social brain. Science, 317(5843), 1344-1347. doi: 10.1126/science. 1145463

Dunn, B. D., Stefanovitch, I., Evans, D., Oliver, C., Hawkins, A., \& Dalgleish, T. (2010). Can you feel the beat? Interoceptive awareness is an interactive function of anxiety- and depressionspecific symptom dimensions. Behav Res Ther, 48(11), 1133-1138. doi: 10.1016/j.brat.2010.07.006

Duquette, M., Roy, M., Lepore, F., Peretz, I., \& Rainville, P. (2007). [Cerebral mechanisms involved in the interaction between pain and emotion]. Rev Neurol (Paris), 163(2), 169-179.

Ehrsson, H. H. (2007). The experimental induction of out-of-body experiences. Science, 317(5841), 1048. doi: 10.1126/science. 1142175

Ehrsson, H. H., Holmes, N. P., \& Passingham, R. E. (2005). Touching a rubber hand: feeling of body ownership is associated with activity in multisensory brain areas. J Neurosci, 25(45), 1056410573.

Eshkevari, E., Rieger, E., Longo, M. R., Haggard, P., \& Treasure, J. (2012). Increased plasticity of the bodily self in eating disorders. Psychol Med, 42(4), 819-828. doi: 10.1017/S0033291711002091

Esposito, G., Yoshida, S., Ohnishi, R., Tsuneoka, Y., Rostagno Mdel, C., Yokota, S., .. . Kuroda, K. O. (2013). Infant calming responses during maternal carrying in humans and mice. Curr Biol, 23(9), 739-745. doi: 10.1016/j.cub.2013.03.041

Farrell, C., Lee, M., \& Shafran, R. (2005). Assessment of body size estimation: a review. European Eating Disorders Review, 13(2), 75-88.

Feinberg, T. E. (1997). Anosognosia and confabulation. In T. E. Feinberg \& M. J. Farah (Eds.), Behavioral Neurology and Neuropsychology (pp. 369-390). New York: McGraw Hill.

Field, T. (2001). Massage Therapy Facilitates Weight Gain in Preterm Infants. Current Directions in Psychological Science, 10(2), 51-54.

Filippetti, M. L., Johnson, M. H., Lloyd-Fox, S., Dragovic, D., \& Farroni, T. (2013). Body perception in newborns. Curr Biol, 23(23), 2413-2416. doi: 10.1016/j.cub.2013.10.017

Fletcher, P., \& Fotopoulou, A. (in press). Abnormalities of agency. In P. Haggard \& B. Eitam (Eds.), Human Agency: Functions and Mechanisms. New York: Oxford University Press.

Fogel, A. (2013). Body Sense. The Science and Practice of Embodied Self-Awareness. New York and London: W.W. Norton \& Company.

Fonagy, P., Gergely, G., Jurist, E. L., \& Target, M. (2004). Affect regulation, mentalization, and the development of self. London: Karnac.

Fotopoulou, A. (2014). Time to get rid of the 'Modular' in neuropsychology: a unified theory of anosognosia as aberrant predictive coding. J Neuropsychol, 8(1), 1-19. doi: 10.1111/jnp. 12010

Fourneret, P., \& Jeannerod, M. (1998). Limited conscious monitoring of motor performance in normal subjects. Neuropsychologia, 36(11), 1133-1140.

Friederich, H. C., Kumari, V., Uher, R., Riga, M., Schmidt, U., Campbell, I. C., . . . Treasure, J. (2006). Differential motivational responses to food and pleasurable cues in anorexia and bulimia nervosa: a startle reflex paradigm. Psychol Med, 36(9), 1327-1335. doi: 10.1017/S0033291706008129

Frith, U., \& Frith, C. (2010). The social brain: allowing humans to boldly go where no other species has been. Philos Trans R Soc Lond B Biol Sci, 365(1537), 165-176.

Gallace, A., \& Spence, C. (2010). The science of interpersonal touch: an overview. Neurosci Biobehav Rev, 34(2), 246-259. doi: 10.1016/j.neubiorev.2008.10.004

Gallagher, S. (2000). Philosophical conceptions of the self: implications for cognitive science. Trends in Cognitive Science, 4(1).

Gallagher, S. (2005). How the Body Shapes the Mind. New York: Oxford University Press.

Gandola, M., Invernizzi, P., Sedda, A., Ferre, E. R., Sterzi, R., Sberna, M., . . Bottini, G. (2012). An anatomical account of somatoparaphrenia. Cortex, 48(9), 1165-1178. doi: 10.1016/j.cortex.2011.06.012 
Gazzola, J. M., Aratani, M. C., Dona, F., Macedo, C., Fukujima, M. M., Gananca, M. M., \& Gananca, F. F. (2009). Factors relating to depressive symptoms among elderly people with chronic vestibular dysfunction. Arq Neuropsiquiatr, 67(2B), 416-422.

Giummarra, M. J., Gibson, S. J., Georgiou-Karistianis, N., \& Bradshaw, J. L. (2008). Mechanisms underlying embodiment, disembodiment and loss of embodiment. Neurosci Biobehav Rev, 32(1), 143-160.

Godemann, F., Linden, M., Neu, P., Heipp, E., \& Dorr, P. (2004). A prospective study on the course of anxiety after vestibular neuronitis. J Psychosom Res, 56(3), 351-354. doi: 10.1016/S00223999(03)00079-5

Gordon, A., Merenstein, J. H., D'Amico, F., \& Hudgens, D. (1998). The effects of therapeutic touch on patients with osteoarthritis of the knee. J Fam Pract, 47(4), 271-277.

Gordon, I., Voos, A. C., Bennett, R. H., Bolling, D. Z., Pelphrey, K. A., \& Kaiser, M. D. (2013). Brain mechanisms for processing affective touch. Hum Brain Mapp, 34(4), 914-922. doi: $10.1002 / \mathrm{hbm} .21480$

Gray, L., Watt, L., \& Blass, E. M. (2000). Skin-to-skin contact is analgesic in healthy newborns. Pediatrics, 105(1), e14.

Grewen, K. M., Anderson, B. J., Girdler, S. S., \& Light, K. C. (2003). Warm partner contact is related to lower cardiovascular reactivity. Behav Med, 29(3), 123-130. doi: 10.1080/08964280309596065

Grunwald, M., Ettrich, C., Krause, W., Assmann, B., Dahne, A., Weiss, T., \& Gertz, H. J. (2001). Haptic perception in anorexia nervosa before and after weight gain. J Clin Exp Neuropsychol, 23(4), 520-529. doi: 10.1076/jcen.23.4.520.1229

$\mathrm{Gu}, \mathrm{X}$. L., \& Yu, L. C. (2007). Involvement of opioid receptors in oxytocin-induced antinociception in the nucleus accumbens of rats. J Pain, 8(1), 85-90. doi: 10.1016/j.jpain.2006.07.001

Guardia, D., Conversy, L., Jardri, R., Lafargue, G., Thomas, P., Dodin, V., . . . Luyat, M. (2012). Imagining one's own and someone else's body actions: dissociation in anorexia nervosa. PLoS One, 7(8), e43241. doi: 10.1371/journal.pone.0043241

Guardia, D., Lafargue, G., Thomas, P., Dodin, V., Cottencin, O., \& Luyat, M. (2010). Anticipation of body-scaled action is modified in anorexia nervosa. Neuropsychologia, 48(13), 3961-3966. doi: 10.1016/j.neuropsychologia.2010.09.004

Harlow, H. F. (1958). The nature of love. American Psychologist, 13, 673-685.

Hart, S., Field, T., Hernandez-Reif, M., Nearing, G., Shaw, S., Schanberg, S., \& Kuhn, C. (2001). Anorexia nervosa symptoms are reduced by massage therapy. Eat Disord, 9(4), 289-299.

Hertenstein, M. J., Keltner, D., App, B., Bulleit, B. A., \& Jaskolka, A. R. (2006). Touch communicates distinct emotions. Emotion, 6(3), 528-533. doi: 10.1037/1528-3542.6.3.528

Hertenstein, M. J., Verkamp, J. M., Kerestes, A. M., \& Holmes, R. M. (2006). The communicative functions of touch in humans, nonhuman primates, and rats: a review and synthesis of the empirical research. Genet Soc Gen Psychol Monogr, 132(1), 5-94.

Husserl, E. (1989). Ideas pertaining to a pure phenomenological philosophy and to a phenomenological philosophy, second book (R. Rojcewicz A. Schuwer, Trans.). Dordrecht: Kluwer Academic Publishers.

Invernizzi, P., Gandola, M., Romano, D., Zapparoli, L., Bottini, G., \& Paulesu, E. (2013). What is mine? Behavioral and anatomical dissociations between somatoparaphrenia and anosognosia for hemiplegia. Behav Neurol, 26(1-2), 139-150. doi: 10.3233/BEN-2012-110226

James, W. (1884). What is an emotion? Mind, 9, 188-205.

James, W. (1890). Principles of psychology. New York: Dover.

Jenkinson, P. M., Haggard, P., Ferreira, N. C., \& Fotopoulou, A. (2013). Body ownership and attention in the mirror: insights from somatoparaphrenia and the rubber hand illusion. Neuropsychologia, 51(8), 1453-1462. doi: 10.1016/j.neuropsychologia.2013.03.029

Jenkinson, P. M., Preston, C., \& Ellis, S. J. (2011). Unawareness after stroke: a review and practical guide to understanding, assessing, and managing anosognosia for hemiplegia. $J$ Clin Exp Neuropsychol, 33(10), 1079-1093. doi: 10.1080/13803395.2011.596822

Johnson, K. O., \& Hsiao, S. S. (1992). Neural mechanisms of tactual form and texture perception. Annu Rev Neurosci, 15, 227-250. doi: 10.1146/annurev.ne.15.030192.001303 
Kammers, M. P., de Vignemont, F., \& Haggard, P. (2010). Cooling the thermal grill illusion through self-touch. Curr Biol, 20(20), 1819-1822. doi: 10.1016/j.cub.2010.08.038

Karnath, H. O., \& Baier, B. (2010). Right insula for our sense of limb ownership and self-awareness of actions. Brain Struct Funct, 214(5-6), 411-417. doi: 10.1007/s00429-010-0250-4

Karnath, H. O., Baier, B., \& Nagele, T. (2005). Awareness of the functioning of one's own limbs mediated by the insular cortex? J Neurosci, 25(31), 7134-7138. doi: 10.1523/JNEUROSCI.1590-05.2005

Kaye, W. (2008). Neurobiology of anorexia and bulimia nervosa. Physiol Behav, 94(1), 121-135. doi: 10.1016/j.physbeh.2007.11.037

Keizer, A., Smeets, M. A., Dijkerman, H. C., van den Hout, M., Klugkist, I., van Elburg, A., \& Postma, A. (2011). Tactile body image disturbance in anorexia nervosa. Psychiatry Res, 190(1), 115-120. doi: 10.1016/j.psychres.2011.04.031

Keizer, A., Smeets, M. A., Postma, A., van Elburg, A., \& Dijkerman, H. C. (2014). Does the experience of ownership over a rubber hand change body size perception in anorexia nervosa patients? Neuropsychologia, 62C, 26-37. doi: 10.1016/j.neuropsychologia.2014.07.003

Keller, E., \& Bzdek, V. M. (1986). Effects of therapeutic touch on tension headache pain. Nurs Res, 35(2), 101-106.

Kerr, C. E., Wasserman, R. H., \& Moore, C. I. (2007). Cortical dynamics as a therapeutic mechanism for touch healing. J Altern Complement Med, 13(1), 59-66.

Kong, J., White, N. S., Kwong, K. K., Vangel, M. G., Rosman, I. S., Gracely, R. H., \& Gollub, R. L. (2006). Using fMRI to dissociate sensory encoding from cognitive evaluation of heat pain intensity. Hum Brain Mapp, 27(9), 715-721. doi: 10.1002/hbm.20213

Korosi, A., Shanabrough, M., McClelland, S., Liu, Z. W., Borok, E., Gao, X. B., . . Baram, T. Z. (2010). Early-life experience reduces excitation to stress-responsive hypothalamic neurons and reprograms the expression of corticotropin-releasing hormone. J Neurosci, 30(2), 703713. doi: 10.1523/JNEUROSCI.4214-09.2010

Krahe, C., Springer, A., Weinman, J. A., \& Fotopoulou, A. (2013). The social modulation of pain: others as predictive signals of salience - a systematic review. Front Hum Neurosci, 7, 386. doi: 10.3389/fnhum.2013.00386

Lenggenhager, B., Tadi, T., Metzinger, T., \& Blanke, O. (2007). Video ergo sum: manipulating bodily self-consciousness. Science, 317(5841), 1096-1099. doi: 10.1126/science.1143439

Lloyd, D. M., Gillis, V., Lewis, E., Farrell, M. J., \& Morrison, I. (2013). Pleasant touch moderates the subjective but not objective aspects of body perception. Front Behav Neurosci, 7, 207.

Löken, L. S., Wessberg, J., Morrison, I., McGlone, F., \& Olausson, H. (2009). Coding of pleasant touch by unmyelinated afferents in humans. Nat Neurosci, 12(5), 547-548.

Longo, M. R., Schuur, F., Kammers, M. P., Tsakiris, M., \& Haggard, P. (2008). What is embodiment? A psychometric approach. Cognition, 107(3), 978-998. doi: 10.1016/j.cognition.2007.12.004

Meltzoff, A. N., \& Brooks, R. (2001). "Like me" as a building block for understanding other minds: Bodily acts, attention, and intention. In B. F. Malle, L. J. Moses \& D. A. Baldwin (Eds.), Intentions and intentionality: Foundations of social cognition (pp. pp. 171-191). Cambridge, MA: MIT Press.

Merleau-Ponty, M. (1962). Phenomenology of Perception (Phénomènologie de la perception published 1945 by Gallimard, Paris). London: Routledge \& Kegan Paul.

Moro, V., Zampini, M., \& Aglioti, S. M. (2004). Changes in spatial position of hands modify tactile extinction but not disownership of contralesional hand in two right brain-damaged patients. Neurocase, 10(6), 437-443. doi: 10.1080/13554790490894020

Morrison, I., Bjornsdotter, M., \& Olausson, H. (2011). Vicarious responses to social touch in posterior insular cortex are tuned to pleasant caressing speeds. J Neurosci, 31(26), 9554-9562. doi: 10.1523/JNEUROSCI.0397-11.2011

Morrison, I., Loken, L. S., \& Olausson, H. (2010). The skin as a social organ. Exp Brain Res, 204(3), 305-314. doi: 10.1007/s00221-009-2007-y

Moseley, G. L., Olthof, N., Venema, A., Don, S., Wijers, M., Gallace, A., \& Spence, C. (2008). Psychologically induced cooling of a specific body part caused by the illusory ownership of an artificial counterpart. Proc Natl Acad Sci U S A, 105(35), 13169-13173. 
Mussgay, L., Klinkenberg, N., \& Ruddel, H. (1999). Heart beat perception in patients with depressive, somatoform, and personality disorders. Journal of Psychophysiology, 13, 293-307.

Neisser, U. (1988). Five kinds of self-knowledge. Philos. Psychology, 1, 35-59.

Nico, D., Daprati, E., Nighoghossian, N., Carrier, E., Duhamel, J. R., \& Sirigu, A. (2010). The role of the right parietal lobe in anorexia nervosa. Psychol Med, 40(9), 1531-1539. doi: $10.1017 /$ S0033291709991851

Niedenthal, P. M. (2007). Embodying emotion. Science, 316(5827), 1002-1005. doi: 10.1126/science. 1136930

Olausson, H., Lamarre, Y., Backlund, H., Morin, C., Wallin, B. G., Starck, G., . . Bushnell, M. C. (2002). Unmyelinated tactile afferents signal touch and project to insular cortex. Nat Neurosci, 5(9), 900-904. doi: 10.1038/nn896

Olausson, H. W., Cole, J., Vallbo, A., McGlone, F., Elam, M., Kramer, H. H., . . Bushnell, M. C. (2008). Unmyelinated tactile afferents have opposite effects on insular and somatosensory cortical processing. Neurosci Lett, 436(2), 128-132.

Paloyelis, Y., Krahe, C., Howard, M., Williams, S., \& Fotopoulou, A. (submitted). Analegic effects of oxytocin in humans: behavioural and electrophysiological evidence.

Panksepp, J. (1998). Affective Neuroscience: The Foundations of Human and Animal Emotions. Oxford: Oxford University Press.

Panksepp, J., \& Burgdorf, J. (2003). "Laughing" rats and the evolutionary antecedents of human joy? Physiol Behav, 79(3), 533-547.

Peelen, M. V., \& Downing, P. E. (2005). Selectivity for the human body in the fusiform gyrus. $J$ Neurophysiol, 93(1), 603-608. doi: 10.1152/jn.00513.2004

Pelaez-Nogueras, M., Field, T. M., Hossain, Z., \& Pickens, J. (1996). Depressed mothers' touching increases infants' positive affect and attention in still-face interactions. Child Dev, 67(4), 1780-1792.

Pollatos, O., Kirsch, W., \& Schandry, R. (2005). On the relationship between interoceptive awareness, emotional experience, and brain processes. Brain Res Cogn Brain Res, 25(3), 948-962. doi: 10.1016/j.cogbrainres.2005.09.019

Pollatos, O., Kurz, A. L., Albrecht, J., Schreder, T., Kleemann, A. M., Schopf, V., . . Schandry, R. (2008). Reduced perception of bodily signals in anorexia nervosa. Eat Behav, 9(4), 381-388. doi: 10.1016/j.eatbeh.2008.02.001

Pollatos, O., \& Schandry, R. (2004). Accuracy of heartbeat perception is reflected in the amplitude of the heartbeat-evoked brain potential. Psychophysiology, 41(3), 476-482. doi: 10.111/14698986.2004.00170.x

Pollatos, O., Traut-Mattausch, E., \& Schandry, R. (2009). Differential effects of anxiety and depression on interoceptive accuracy. Depress Anxiety, 26(2), 167-173. doi: $10.1002 /$ da. 20504

Prinz, W. (2012). Open Minds: The Social Making of Agency and Intentionality. Cambridge, MA: MIT Press.

Rainville, P., Bao, Q. V., \& Chretien, P. (2005). Pain-related emotions modulate experimental pain perception and autonomic responses. Pain, 118(3), 306-318. doi: 10.1016/j.pain.2005.08.022

Reddy, V. (2008). How Infants Know Minds. Cambridge MA/London: Harvard University Press.

Rizzolatti, G., \& Craighero, L. (2004). The mirror-neuron system. Annu Rev Neurosci, 27, 169-192.

Rochat, P. (2009). Others in Mind: Social Origins of Self-Consciousness. New York, NY: Cambridge University Press.

Romano, D., Gandola, M., Bottini, G., \& Maravita, A. (2014). Arousal responses to noxious stimuli in somatoparaphrenia and anosognosia: clues to body awareness. Brain, 137(Pt 4), 1213-1223. doi: 10.1093/brain/awu009

Roy, M., Piche, M., Chen, J. I., Peretz, I., \& Rainville, P. (2009). Cerebral and spinal modulation of pain by emotions. Proc Natl Acad Sci U S A, 106(49), 20900-20905. doi: 10.1073/pnas.0904706106

Royet, J. P., Plailly, J., Delon-Martin, C., Kareken, D. A., \& Segebarth, C. (2003). fMRI of emotional responses to odors: influence of hedonic valence and judgment, handedness, and gender. Neuroimage, 20(2), 713-728. doi: 10.1016/S1053-8119(03)00388-4 
Sander, D. (2013). Models of Emotion. The Affective Neuroscience Approach. Cambridge: Cambridge University Press.

Schaefer, M., Egloff, B., Gerlach, A. L., \& Witthoft, M. (2014). Improving heartbeat perception in patients with medically unexplained symptoms reduces symptom distress. Biol Psychol, 101, 69-76. doi: 10.1016/j.biopsycho.2014.05.012

Schaefer, M., Egloff, B., \& Witthoft, M. (2012). Is interoceptive awareness really altered in somatoform disorders? Testing competing theories with two paradigms of heartbeat perception. J Abnorm Psychol, 121(3), 719-724. doi: 10.1037/a0028509

Schandry, R. (1981). Heart beat perception and emotional experience. Psychophysiology, 18(4), 483488.

Schreckenberger, M., Siessmeier, T., Viertmann, A., Landvogt, C., Buchholz, H. G., Rolke, R., . . Birklein, F. (2005). The unpleasantness of tonic pain is encoded by the insular cortex. Neurology, 64(7), 1175-1183. doi: 10.1212/01.WNL.0000156353.17305.52

Schütz-Bosbach, S., Musil, J. J., \& Haggard, P. (2009). Touchant-touche: the role of self-touch in the representation of body structure. Conscious Cogn, 18(1), 2-11.

Schütz-Bosbach, S., Tausche, P., \& Weiss, C. (2009). Roughness perception during the rubber hand illusion. Brain Cogn, 70(1), 136-144.

Sebanz, N., Bekkering, H., \& Knoblich, G. (2006). Joint action: bodies and minds moving together. Trends Cogn Sci, 10(2), 70-76.

Sedda, A. (2011). Body integrity identity disorder: from a psychological to a neurological syndrome. Neuropsychol Rev, 21(4), 334-336.

Serino, A., \& Haggard, P. (2010). Touch and the body. Neurosci Biobehav Rev, 34(2), 224-236.

Seth, A. K. (2013). Interoceptive inference, emotion, and the embodied self. Trends Cogn Sci, 17(11), 565-573. doi: 10.1016/j.tics.2013.09.007

Seth, A. K., Suzuki, K., \& Critchley, H. D. (2011). An interoceptive predictive coding model of conscious presence. Front Psychol, 2, 395. doi: 10.3389/fpsyg.2011.00395

Sforza, A., Bufalari, I., Haggard, P., \& Aglioti, S. M. (2010). My face in yours: Visuo-tactile facial stimulation influences sense of identity. Soc Neurosci, 5(2), 148-162. doi: 10.1080/17470910903205503

Sharp, H., Pickles, A., Meaney, M., Marshall, K., Tibu, F., \& Hill, J. (2012). Frequency of infant stroking reported by mothers moderates the effect of prenatal depression on infant behavioural and physiological outcomes. PLoS One, 7(10), e45446. doi: 10.1371/journal.pone.0045446

Simeon, D., Gross, S., Guralnik, O., Stein, D. J., Schmeidler, J., \& Hollander, E. (1997). Feeling unreal: 30 cases of DSM-III-R depersonalization disorder. Am J Psychiatry, 154(8), 11071113.

Small, D. M., Gregory, M. D., Mak, Y. E., Gitelman, D., Mesulam, M. M., \& Parrish, T. (2003). Dissociation of neural representation of intensity and affective valuation in human gustation. Neuron, 39(4), 701-711.

Smeets, M. A., Smit, F., Panhuysen, G. E., \& Ingleby, J. D. (1998). Body perception index: benefits, pitfalls, ideas. $J$ Psychosom Res, 44(3-4), 457-464.

Soussignan, R., Schaal, B., Rigaud, D., Royet, J. P., \& Jiang, T. (2011). Hedonic reactivity to visual and olfactory cues: rapid facial electromyographic reactions are altered in anorexia nervosa. Biol Psychol, 86(3), 265-272. doi: 10.1016/j.biopsycho.2010.12.007

Stevens, J., Schmied, V., Burns, E., \& Dahlen, H. (2014). Immediate or early skin-to-skin contact after a Caesarean section: a review of the literature. Matern Child Nutr.

Stevens, S., Gerlach, A. L., Cludius, B., Silkens, A., Craske, M. G., \& Hermann, C. (2011). Heartbeat perception in social anxiety before and during speech anticipation. Behav Res Ther, 49(2), 138-143. doi: 10.1016/j.brat.2010.11.009

Strigo, I. A., Matthews, S. C., Simmons, A. N., Oberndorfer, T., Klabunde, M., Reinhardt, L. E., \& Kaye, W. H. (2013). Altered insula activation during pain anticipation in individuals recovered from anorexia nervosa: evidence of interoceptive dysregulation. Int J Eat Disord, 46(1), 23-33. doi: 10.1002/eat.22045 
Suchan, B., Busch, M., Schulte, D., Gronemeyer, D., Herpertz, S., \& Vocks, S. (2010). Reduction of gray matter density in the extrastriate body area in women with anorexia nervosa. Behav Brain Res, 206(1), 63-67. doi: 10.1016/j.bbr.2009.08.035

Sullivan, P. F. (1995). Mortality in anorexia nervosa. Am J Psychiatry, 152(7), 1073-1074.

Suzuki, K., Garfinkel, S. N., Critchley, H. D., \& Seth, A. K. (2013). Multisensory integration across exteroceptive and interoceptive domains modulates self-experience in the rubber-hand illusion. Neuropsychologia, 51(13), 2909-2917. doi: 10.1016/j.neuropsychologia.2013.08.014

Tajadura-Jimenez, A., Longo, M. R., Coleman, R., \& Tsakiris, M. (2012). The person in the mirror: using the enfacement illusion to investigate the experiential structure of self-identification. Conscious Cogn, 21(4), 1725-1738. doi: 10.1016/j.concog.2012.10.004

Tchanturia, K., Davies, H., Harrison, A., Fox, J. R., Treasure, J., \& Schmidt, U. (2012). Altered social hedonic processing in eating disorders. Int J Eat Disord, 45(8), 962-969. doi: 10.1002/eat.22032

Trevarthen, C. (1993). The function of emotions in early infant communication and development. In J. Nadel \& L. Camaioni (Eds.), New Perspectives in Early Communicative Development (pp. pp. 48-81). London: Routledge.

Tsakiris, M. (2010). My body in the brain: a neurocognitive model of body-ownership. Neuropsychologia, 48(3), 703-712. doi: 10.1016/j.neuropsychologia.2009.09.034

Tsakiris, M., Hesse, M. D., Boy, C., Haggard, P., \& Fink, G. R. (2007). Neural signatures of body ownership: a sensory network for bodily self-consciousness. Cereb Cortex, 17(10), 22352244. doi: 10.1093/cercor/bhl131

Tsakiris, M., Tajadura-Jimenez, A., \& Costantini, M. (2011). Just a heartbeat away from one's body: interoceptive sensitivity predicts malleability of body-representations. Proc Biol Sci, 278(1717), 2470-2476. doi: 10.1098/rspb.2010.2547

Uher, R., Murphy, T., Friederich, H. C., Dalgleish, T., Brammer, M. J., Giampietro, V., .. . Treasure, J. (2005). Functional neuroanatomy of body shape perception in healthy and eatingdisordered women. Biol Psychiatry, 58(12), 990-997. doi: 10.1016/j.biopsych.2005.06.001

Urgesi, C., Fornasari, L., Canalaz, F., Perini, L., Cremaschi, S., Faleschini, L., . . Brambilla, P. (2013). Impaired configural body processing in anorexia nervosa: Evidence from the body inversion effect. Br J Psychol. doi: 10.1111/bjop.12057

Valentini, M., Kischka, U., \& Halligan, P. W. (2008). Residual haptic sensation following stroke using ipsilateral stimulation. J Neurol Neurosurg Psychiatry, 79(3), 266-270.

Vallar, G., \& Ronchi, R. (2009). Somatoparaphrenia: a body delusion. A review of the neuropsychological literature. Exp Brain Res, 192(3), 533-551.

Vallbo, A. B., Olausson, H., \& Wessberg, J. (1999). Unmyelinated afferents constitute a second system coding tactile stimuli of the human hairy skin. J Neurophysiol, 81(6), 2753-2763.

Vallee, M., MacCari, S., Dellu, F., Simon, H., Le Moal, M., \& Mayo, W. (1999). Long-term effects of prenatal stress and postnatal handling on age-related glucocorticoid secretion and cognitive performance: a longitudinal study in the rat. Eur J Neurosci, 11(8), 2906-2916.

Van den Stock, J., Vandenbulcke, M., Sinke, C. B., \& de Gelder, B. (2014). Affective scenes influence fear perception of individual body expressions. Hum Brain Mapp, 35(2), 492-502. doi: 10.1002/hbm.22195

van Stralen, H. E., van Zandvoort, M. J., \& Dijkerman, H. C. (2011). The role of self-touch in somatosensory and body representation disorders after stroke. Philos Trans R Soc Lond B Biol Sci, 366(1581), 3142-3152. doi: 10.1098/rstb.2011.0163

van Stralen, H. E., van Zandvoort, M. J., Hoppenbrouwers, S. S., Vissers, L. M., Kappelle, L. J., \& Dijkerman, H. C. (2014). Affective touch modulates the rubber hand illusion. Cognition, 131(1), 147-158.

Wagner, A., Aizenstein, H., Mazurkewicz, L., Fudge, J., Frank, G. K., Putnam, K., . . Kaye, W. H. (2008). Altered insula response to taste stimuli in individuals recovered from restricting-type anorexia nervosa. Neuropsychopharmacology, 33(3), 513-523. doi: 10.1038/sj.npp.1301443

Wagner, A., Aizenstein, H., Venkatraman, V. K., Fudge, J., May, J. C., Mazurkewicz, L., . . Kaye, W. H. (2007). Altered reward processing in women recovered from anorexia nervosa. Am J Psychiatry, 164(12), 1842-1849. doi: 10.1176/appi.ajp.2007.07040575 
Warnock, F. F., Castral, T. C., Brant, R., Sekilian, M., Leite, A. M., Owens Sde, L., \& Scochi, C. G. (2010). Brief report: Maternal kangaroo care for neonatal pain relief: a systematic narrative review. J Pediatr Psychol, 35(9), 975-984.

Weiskrantz, L., \& Zhang, D. (1987). Residual tactile sensitivity with self-directed stimulation in hemianaesthesia. Journal of Neurology, Neurosurgery \& Psychiatry, 50, 632-634.

Weiss, W. J., Wilson, P. W., \& Morrison, D. (2004). Maternal tactile stimulation and the neurodevelopment of low birth weight infants. Infancy, 5, 85-107.

White, R. C., Aimola Davies, A. M., Halleen, T. J., \& Davies, M. (2010). Tactile expectations and the perception of self-touch: an investigation using the rubber hand paradigm. Conscious Cogn, 19(2), 505-519.

White, R. C., Aimola Davies, A. M., Kischka, U., \& Davies, M. (2011). Touch and feel? Using the rubber hand paradigm to investigate self-touch enhancement in right-hemisphere stroke patients. Neuropsychologia, 48(1), 26-37.

Winnicott, D. W. (1971). Mirror role of mother and family in child development. In D. W. Winnicott (Ed.), Playing and Reality (pp. 149-159). London and New York: Routledge Classics.

Woods, D. L., Craven, R. F., \& Whitney, J. (2005). The effect of therapeutic touch on behavioral symptoms of persons with dementia. Altern Ther Health Med, 11(1), 66-74.

Woods, D. L., \& Dimond, M. (2002). The effect of therapeutic touch on agitated behavior and cortisol in persons with Alzheimer's disease. Biol Res Nurs, 4(2), 104-114.

Zeller, D., Gross, C., Bartsch, A., Johansen-Berg, H., \& Classen, J. (2011). Ventral premotor cortex may be required for dynamic changes in the feeling of limb ownership: a lesion study. $J$ Neurosci, 31(13), 4852-4857. doi: 10.1523/JNEUROSCI.5154-10.2011 


\section{Figure Legends}

Figure 1. Simplified schematic figure of the bottom-up sensory signals and the topdown mechanisms underlying mental representations of the bodily self. Multiple sensory and emotional signals, including those conveyed via affective touch, are integrated depending on top-down modulatory mechanisms in order to allow for the experience of bodily ownership and the location of our self-awareness inside our physical body. This mechanism of integration of somatic experiences with other internal and external signals is thought to contribute in the first place to a low-level pre-reflective form of immediate bodily selfawareness. This representation interacts with conceptual self-knowledge of the 'extended self', based on episodic memory, background beliefs and contextual cues. Note that there are intrinsic connections between sensory, cognitive and socio-emotional processes at each level of self-awareness, which, for reasons of simplicity, are not detailed here. Abnormalities in the weighing and integration of bottom-up and top-down signals may lead to 'body image' disturbances as in anorexia nervosa (see section 3.2), or to a disturbance in the sense of body ownership as seen in asomatognosic patients following right-hemisphere brain damage (see section 3.3).

Figure 2. (a) Median and interquartile range (error bars) of pleasantness rating scores for slow and fast stroking. b) Median and interquartile range (error bars) of change in embodiment of the rubber/real hand for synchronous (dark grey bars) and asynchronous (light grey bars) stroking. This figure is reproduced from Crucianelli et al. (2013). 